\title{
Correction of Hyperglycemia with Phlorizin Normalizes Tissue Sensitivity to Insulin in Diabetic Rats
}

\author{
Luciano Rossetti, Douglas Smith, Gerald I. Shulman, Dimitrios Papachristou, and Ralph A. Defronzo \\ Yale University, School of Medicine, New Haven, Connecticut 06510
}

\begin{abstract}
Insulin resistance is characteristic of the diabetic state. To define the role of hyperglycemia in generation of the insulin resistance, we examined the effect of phlorizin treatment on tissue sensitivity to insulin in partially pancreatectomized rats. Five groups were studied: group I, sham-operated controls; group II, partially pancreatectomized diabetic rats with moderate glucose intolerance; group III, diabetic rats treated with phlorizin to normalize glucose tolerance; group IV, phlorizin-treated controls; and group $\mathrm{V}$, phlorizin-treated diabetic rats restudied after discontinuation of phlorixin. Insulin sensitivity was assessed with the euglyemic hyperinsulinemic clamp technique in awake, unstressed rats. Insulin-mediated glucose metabolism was reduced by approximately $30 \%(P<0.001)$ in diabetic rats. Phlorizin treatment of diabetic rats completely normalized insulin sensitivity but had no effect on insulin action in controls. Discontinuation of phlorizin in phlorizin-treated diabetic rats resulted in the reemergence of insulin resistance. These data demonstrate that $(a)$ a reduction of $\beta$-cell mass leads to the development of insulin resistance, and (b) correction of hyperglycemia with phlorizin, without change in insulin levels, normalizes insulin sensitivity. These results provide the first in vivo evidence that hyperglycemia per se can lead to the development of insulin resistance.
\end{abstract}

\section{Introduction}

Defects in insulin secretion (1-3) and insulin action (3-8) are universally present in both insulin-dependent (IDDM) ${ }^{1}$ and noninsulin-dependent (NIDDM) diabetes mellitus in man, and similar disturbances have been demonstrated in animal models of diabetes (9-14). It is now clear that an initial defect in insulin secretion by the pancreas can lead to the development of insulin resistance (9-13). However, the precise contributions of insulin deficiency versus hyperglycemia to the impairment in insulin action have not been defined. Recent studies have provided evidence that hyperglycemia per se may contribute to the defect in insulin secretion by the $\beta$-cell in some animal models of diabetes mellitus $(15,16)$. Further, Unger and Grundy have advanced the hypothesis that hyperglycemia may also, in part, be

Address all correspondence to Dr. Ralph A. DeFronzo, 2071 LMP Bldg., Yale-New Haven Hospital, 333 Cedar St., New Haven, CT 06510.

Received for publication 25 August 1986.

1. Abbreviations used in this paper: IDDM, insulin-dependent diabetes mellitus; MTT, meal tolerance test; NIDDM, non-insulin-dependent diabetes mellitus; OGTT, oral glucose tolerance test.

J. Clin. Invest.

(c) The American Society for Clinical Investigation, Inc. 0021-9738/87/05/1510/06 \$1.00

Volume 79, May 1987, 1510-1515 responsible for the impairment in insulin-mediated glucose disposal which is observed in both NIDDM and IDDM subjects $(17,18)$. However, experimental validation of this later thesis has not yet been provided. In the present study we have examined the effect of phlorizin treatment on tissue sensitivity to insulin in a partially pancreatectomized diabetic rat model. By inhibiting glucose transport through the renal tubule, phlorizin normalizes plasma glucose without altering insulin secretion. Our results indicated that correction of hyperglycemia per se leads to a normalization of the body's sensitivity to insulin, and suggested that chronic hyperglycemia may play an important role in perpetuating the metabolic deterioration, characteristic of the diabetic state.

\section{Methods}

Experimental protocol. Four groups of male Sprague-Dawley rats (Charles River Breeding Laboratories, Inc., Wilmington, MA) were studied: group I, sham-operated controls $(n=14)$; group II, partially pancreatectomized rats $(n=19)$; group III, partially pancreatectomized phlorizin-treated rats $(n=10)$; group IV, sham-operated phlorizin-treated rats $(n=7)$ that served as a control for the effect of phlorizin. Group V $(n=4)$ consisted of four partially pancreatectomized rats from group III that were restudied $2 \mathrm{wk}$ after discontinuation of phlorizin. At 3-4 wk of age, all rats (80-100 g) were anesthetized with phenobarbital and, in groups II and III, $90 \%$ of their pancreas was removed according to Foglia's technique (19), as modified by Bonner-Weir et al. (15). Groups I and IV underwent a sham pancreatectomy in which the pancreas was disengaged from the mesentery and gently rubbed between the fingers. Phlorizin $(0.4 \mathrm{~g} / \mathrm{kg}$ body wt per d; made up as a $20 \%$ solution in propylene glycol) treatment (groups III and IV) was initiated 10-12 d after surgery, at a time when hyperglycemia first became evident in the partially pancreatectomized rats, and was continued for 4-5 wk. Phlorizin was administered as a subcutaneous injection in three equally divided doses that were given at 8-h intervals to ensure continuous, day-long inhibition of renal tubular glucose reabsorption. Rats in groups I and II received vehicle injection only. The last dose of phlorizin was given $15 \mathrm{~h}$ before the insulin-clamp study, and the absence of glucosuria was ascertained in all rats for all five groups at the end of the insulin-clamp study.

Immediately after surgery (i.e., pancreatectomy or sham pancreatectomy), rats were housed in individual cages and subjected to a standard light (6 a.m. to 6 p.m.)-dark (6 p.m. to 6 a.m.) cycle. Based on past experience, rats received the identical daily allotment of Rat Chow (Ralston-Purina Co., St. Louis, MO) in an amount $(0.1 \mathrm{~g} / \mathrm{g}$ body wt per $\mathrm{d})$ that sustained normal growth and that was completely consumed by all of the animals.

After surgery rats were weighed twice weekly and at the same time tail vein blood collected for the determination of fed plasma glucose concentration. A fasting plasma glucose concentration was also determined twice weekly on tail vein blood. $5 \mathrm{wk}$ after pancreatectomy/sham operation and $1 \mathrm{wk}$ before performing the insulin-clamp study, rats were anesthetized with phenobarbital $(50 \mathrm{mg} / \mathrm{kg}$ body wt) and indwelling catheters inserted so that the animals could be studied in the awake, unstressed state. Two internal jugular catheters were inserted and extended to the level of the right atrium and a left carotid catheter was advanced to the level of the aortic arch. The three catheters were filled with heparin/ polyvinylpyrrolidone solution, sealed, and tunneled subcutaneously 
around the side of the neck to the back of the head. The catheters were externalized through a skin incision and anchored to the skull with a dental cement cap.

Meal tolerance test (MTT). $4 \mathrm{~d}$ after insertion of the catheters, rats in groups I-IV received an MTT. Four rats in group V received an MTT $12 \mathrm{~d}$ after discontinuation of the phlorizin. At 8 a.m., after an overnight fast, the heparin/polyvinylpyrrolidone solution was aspirated from one of the venous catheters and catheter patency was maintained by a slow, continuous infusion of isotonic saline. Rats spontaneously consumed 4 $\mathrm{g}$ of Rat Chow (Ralston-Purina Co.) over $30 \mathrm{~min}$. In groups I-IV, blood samples were obtained from the venous line for the determination of plasma glucose concentration, at 0,60 , and $120 \mathrm{~min}$ after food ingestion and for that of plasma insulin, at 0 and $60 \mathrm{~min}$. In group $\mathrm{V}$, plasma glucose concentration was measured at 0 and 120 min only, and samples for plasma insulin were not drawn during the MTT.

Oral glucose tolerance test (OGTT). $6 \mathrm{~d}$ after catheter insertion, rats in groups I (sham-operated controls) and II (partial pancreatectomy) were fasted overnight and received $1 \mathrm{~g} / \mathrm{kg}$ of glucose by gastric gavage. Blood samples for plasma glucose and insulin determination were obtained from the indwelling venous catheter at 0,60 , and $120 \mathrm{~min}$, as described above.

Insulin-clamp study. $8 \mathrm{~d}$ after catheter insertion, rats in groups I-IV received a two-step euglycemic insulin-clamp study $(20,21)$. Four rats in group III received a repeat two-step insulin-clamp study $14 \mathrm{~d}$ after stopping the phlorizin. At 8 a.m., after an overnight fast, the heparin/ polyvinylpyrrolidone solution was aspirated and catheter patency maintained by a slow continuous infusion $(15 \mu \mathrm{l} / \mathrm{min})$ of isotonic saline. The venous catheter was used for blood withdrawal and the arterial catheter used for infusion of all test substances. As in the MTT and OGTT, the catheters were suspended on a pulley system to allow free movement of the rat in the cage throughout the insulin-clamp study. To prevent intravascular volume depletion and anemia, fresh whole blood (diluted 1:1 in heparinized saline) obtained by heart puncture from littermates of the test animal was administered at a constant rate $(15 \mu \mathrm{l} / \mathrm{min})$, designed to replace quantitatively the total blood loss during the study. 60 min before starting the insulin clamp, a prime $(6 \mu \mathrm{Ci})$-continuous $(0.1$ $\mu \mathrm{Ci} / \mathrm{min}$ ) infusion of $\left[{ }^{3} \mathrm{H}-3\right]$ glucose (New England Nuclear, Boston, MA) was initiated and continued throughout the study (20). Plasma samples for the determination of tritiated glucose specific activity were obtained at 5-min intervals from 30 to $0 \mathrm{~min}$, and at $5-10$-min intervals after starting the insulin infusion. At time zero, a two-step euglycemic insulin clamp was begun (20). A prime-continuous $(2.4 \mathrm{mU} / \mathrm{kg} \cdot \mathrm{min})$ infusion of regular insulin (Eli Lilly \& Co., Indianapolis, IN) was administered at time $0-90 \mathrm{~min}$ to acutely raise and maintain the plasma insulin concentration by $\sim 80-90 \mu \mathrm{U} / \mathrm{ml}$. At $90 \mathrm{~min}$, the insulin space was reprimed and the continuous insulin infusion rate increased to $4.8 \mathrm{mU} / \mathrm{kg} \cdot \mathrm{min}$ to maintain the plasma insulin concentration at $\sim 170-180 \mu \mathrm{U} / \mathrm{ml}$ until $180 \mathrm{~min}$. The insulin was dissolved in $1 \mathrm{ml}$ of whole rat blood and $3 \mathrm{ml}$ of isotonic saline. In all groups a variable infusion of $25 \%$ glucose was started at time zero and adjusted to clamp the plasma glucose concentration at $\sim 100 \mathrm{mg} / \mathrm{dl}$. In group II the glucose infusion was not started until a mean of $8 \mathrm{~min}$ after starting the insulin at which time the fasting plasma glucose concentration $(124 \mathrm{mg} / \mathrm{dl})$ had declined to $100 \mathrm{mg} / \mathrm{dl}$. Samples for plasma insulin determination were obtained at 15-30-min intervals throughout the $180 \mathrm{~min}$ insulin-clamp study. At the end of each insulin-clamp study, urine was collected and assayed for glucose.

Insulin-clamp reproducibility. To test the reproducibility of the insulin-clamp technique, five diabetic rats received a $4.8 \mathrm{mU} / \mathrm{kg} \cdot \mathrm{min}$ euglycemic insulin-clamp study on two different occasions. The clamper did not know the identity of the rats at the time of study.

Analytical procedures. Plasma glucose was measured by the glucose oxidase method using a glucose analyzer (Beckman Instruments, Inc., Spinco Div, Palo Alto, CA) and plasma insulin by radioimmunoassay using porcine insulin standards. Plasma $\left[{ }^{3} \mathrm{H}-3\right]$ glucose radioactivity was measured in duplicate on the supernatants of barium hydroxide-zinc sulphate precipitates (Somogyi procedure) of plasma samples after evaporation to dryness, to eliminate tritiated water.

Calculations. Data for total body glucose uptake and suppression of hepatic glucose production represent the mean of values during the last $30 \mathrm{~min}$ of the $2.4 \mathrm{mU} / \mathrm{kg} \cdot \min$ (i.e., $60-90-\mathrm{min}$ period) and the $4.8 \mathrm{mU} /$ $\mathrm{kg} \cdot \mathrm{min}$ (i.e., $150-180 \mathrm{~min}$ period) insulin-clamp studies. This time period was chosen to allow insulin to more fully exert its biologic effects. Qualitatively similar results are obtained if one compares the initial $60-\mathrm{min}$ or entire 90 -min period of hyperinsulinemia. Total body glucose disposal was calculated by adding the rate of residual hepatic glucose production during the last $30 \mathrm{~min}$ of each insulin-clamp step to the glucose infusion rate during the same 30 -min period. All values are presented as the mean \pm SEM. Differences between groups were determined using the one way analysis of variance in conjunction with the Student-Newman-Kuel's test.

\section{Results}

There were no differences in the mean body weights between groups I-IV (Table I). Rats in group V weighed slightly more than those in groups I-IV. Both the fasting $(P<0.05)$ and fed $(P<0.001)$ plasma glucose concentrations (mean of four determinations) during the 2-wk-period before the insulin-clamp study were significantly higher in the two diabetic groups (II and V) compared with the other three groups (I, III, and IV) $(P$ $<0.05$ ) (Table I). The fasting plasma insulin concentration was similar in all five groups. In five diabetic rats we sequentially followed the decline in plasma glucose concentration during the overnight fast. The initial fed plasma glucose concentration was $303 \pm 14 \mathrm{mg} / \mathrm{dl}$. After $6 \mathrm{~h}$ of fasting, the plasma glucose concentration had declined to $130 \pm 4 \mathrm{mg} / \mathrm{dl}$, and with little further change, at $12 \mathrm{~h}$ it averaged $121 \pm 3 \mathrm{mg} / \mathrm{dl}$.

During the OGTT the incremental area under the curve and the rise in plasma glucose concentration at both 1 and $2 \mathrm{~h}$ were $\sim$ half as large in the controls (group I) compared with diabetics (group II) $(P<0.001)$, whereas the postglucose plasma insulin response was markedly impaired in the diabetics $(P<0.001)$ (Table I). During the MTT, the incremental area under the curve and the rise in plasma glucose concentration at 1 and $2 \mathrm{~h}$ were also half as large in the controls (group I) versus diabetics (group II) $(P<0.001)$, whereas the plasma insulin response at $1 \mathrm{~h}$ was significantly less in diabetics $(P<0.001)$ (Table I). In phlorizintreated diabetic rats (group III) the fasting plasma glucose concentration was normalized and the incremental area under the glucose curve was not significantly different from controls (group I). The 1-h postmeal plasma glucose concentration was similar to that of sham-operated controls (group I), even though the plasma insulin concentration failed to increase above that observed in the diabetic group (Table I). However, at $2 \mathrm{~h}$ during the MTT, a modest increase in the plasma glucose concentration persisted. Phlorizin administration to sham-operated animals had no effect on the plasma glucose and insulin responses during the MTT (Table I). When phlorizin was discontinued in group III and the rats were restudied (group V), the plasma glucose response during the MTT was nearly identical to that in the diabetic (group II) rats.

The results of the two-step insulin-clamp study are shown in Table II. Steady state plasma glucose and insulin concentrations during both hyperinsulinemic steps were similar in all five groups. The coefficients of variation in plasma glucose and insulin were $<5$ and $10 \%$, respectively in all five groups. In diabetic (group II) rats insulin-mediated glucose disposal was reduced by 29 and $27 \%$ respectively $(P<0.001)$ compared with sham-operated controls (group I) during the 2.4 and $4.8 \mathrm{mU} / \mathrm{kg} \cdot \mathrm{min}$ insulin-clamp steps. Phlorizin treatment of diabetic rats completely restored tissue sensitivity to normal. Phlorizin itself had 
Table I. Plasma Glucose and Insulin Concentrations in the Fasting and Fed States and during MTT and OGTT

\begin{tabular}{|c|c|c|c|c|c|c|c|c|c|c|c|}
\hline \multirow[b]{3}{*}{ Group } & \multirow[b]{3}{*}{ No. } & \multirow[b]{3}{*}{$\mathrm{Wt}^{*}$} & \multirow{3}{*}{$\begin{array}{l}\text { Fasting plasma } \\
\text { glucose }^{*}\end{array}$} & \multirow{3}{*}{$\begin{array}{l}\text { Fed plasma } \\
\text { glucose }^{\ddagger}\end{array}$} & & \multicolumn{6}{|c|}{ MTT or OGTT } \\
\hline & & & & & & \multicolumn{3}{|c|}{ Plasma glucose $(m g / d l)$} & \multicolumn{3}{|c|}{ Plasma insulin $(\mu U / m l)$} \\
\hline & & & & & & $0 \mathrm{~min}$ & $60 \mathrm{~min}$ & $120 \mathrm{~min}$ & $0 \mathrm{~min}$ & $60 \mathrm{~min}$ & $120 \mathrm{~min}$ \\
\hline & & $g$ & $m g / d l$ & $m g / d l$ & & & & & & & \\
\hline \multirow[t]{2}{*}{ I Sham operated } & 14 & $260 \pm 7$ & $101 \pm 2$ & $140 \pm 1$ & MTT & $98 \pm 2$ & $147 \pm 3$ & $127 \pm 2$ & $14 \pm 1$ & $44 \pm 4$ & NM \\
\hline & & & & & OGTT & $101 \pm 2$ & $152 \pm 3$ & $118 \pm 2$ & $16 \pm 1$ & $63 \pm 8$ & $61 \pm 6$ \\
\hline \multirow[t]{2}{*}{ II Diabetic } & 19 & $269 \pm 7$ & $122 \pm 5^{8}$ & $295 \pm 12^{1}$ & MTT & $112 \pm 3^{8}$ & $324 \pm 11^{\prime}$ & $263 \pm 12^{9}$ & $14 \pm 1$ & $18 \pm 2$ & NM \\
\hline & & & & & OGTT & $122 \pm 5^{\prime}$ & $291 \pm 17^{4}$ & $212 \pm 24^{\prime}$ & $14 \pm 1$ & $19 \pm 2^{1}$ & $26 \pm 3^{9}$ \\
\hline \multirow{2}{*}{$\begin{array}{l}\text { III Diabetic plus } \\
\text { phlorizin }\end{array}$} & 10 & $264 \pm 8$ & $100 \pm 3$ & $171 \pm 4$ & MTT & $98 \pm 3$ & $160 \pm 5$ & $158 \pm 5$ & $13 \pm 1$ & $20 \pm 3$ & NM \\
\hline & & & & & OGTT & - & - & - & - & - & - \\
\hline \multirow{2}{*}{$\begin{array}{l}\text { IV Sham-operated plus } \\
\text { phlorizin }\end{array}$} & 7 & $269 \pm 10$ & $99 \pm 3$ & $137 \pm 2$ & MTT & $100 \pm 3$ & $141 \pm 6$ & $104 \pm 2$ & $15 \pm 1$ & $49 \pm 3$ & NM \\
\hline & & & & & OGTT & - & - & - & - & - & - \\
\hline $\begin{array}{l}\text { V Phlorizin-treated } \\
\text { diabetics after } \\
\text { stopping phlorizin }\end{array}$ & 4 & $286 \pm 11$ & $113 \pm 3$ & $306 \pm 45^{\prime}$ & MTT & $113 \pm 3^{8}$ & - & $306 \pm 45^{1}$ & - & - & - \\
\hline
\end{tabular}

All values represent the mean \pm SEM. NM, not measured. * Represents the mean weight 6 wk after surgery, at the time the insulin-clamp study was performed in groups I-IV and at $8 \mathrm{wk}$ after surgery in group V. ${ }^{\ddagger}$ Represents the mean of four values for each rat during the 2-wk-period before performing the insulin-clamp study. ${ }^{\&} P<0.05$ versus groups I, III, and IV. ' $P<0.001$ versus groups I, III and IV.

no effect on insulin-mediated glucose disposal in sham-operated animals. When phlorizin was discontinued in diabetic rats (group V), insulin-mediated glucose disposal decreased to a level that was similar to that observed in group II diabetic animals $(P$ $<0.001$ vs. controls).

Glucosuria (8-9 g/dl) was present in all diabetic rats (groups III and V) while they were receiving three times the daily injec- tions of phlorizin. Glucosuria $(0.7-0.8 \mathrm{~g} / \mathrm{dl})$ was also present in diabetic rats not treated with phlorizin (groups II and V), but at a concentration $\sim$ one-tenth of that observed in group III. 24h urine vol and glucose excretion were not quantitated. Only trace $(<0.1 \mathrm{~g} / \mathrm{dl})$ amounts of glucose were detected in the urine from sham-operated phlorizin-treated rats.

Glucosuria was not detected in the five groups during any

Table II. Plasma Insulin and Glucose Concentrations, Hepatic Glucose Production, and Total Body Glucose Uptake during the Euglycemic Clamp Studies

\begin{tabular}{|c|c|c|c|c|c|c|}
\hline Group & No. & $\begin{array}{l}\text { Insulin } \\
\text { infusion rate }\end{array}$ & $\begin{array}{l}\text { Steady state } \\
\text { plasma insulin }\end{array}$ & $\begin{array}{l}\text { Steady state } \\
\text { plasma glucose }\end{array}$ & $\begin{array}{l}\text { Hepatic glucose } \\
\text { production }\end{array}$ & Glucose uptake \\
\hline & & $\mathrm{mU} / \mathrm{kg} \cdot \min$ & $\mu U / m l$ & $m g / d l$ & $\mathrm{mg} / \mathrm{kg} \cdot \min$ & $\mathrm{mg} / \mathrm{kg} \cdot \min$ \\
\hline \multirow[t]{3}{*}{ I Sham operated } & 14 & 0 & $14 \pm 1$ & $101 \pm 2$ & $6.82 \pm 0.60$ & $6.82 \pm 0.60$ \\
\hline & & 2.4 & $82 \pm 4$ & $100 \pm 1$ & $0.79 \pm 0.09$ & $18.8 \pm 0.50$ \\
\hline & & 4.8 & $168 \pm 5$ & $102 \pm 1$ & $0.18 \pm 0.07$ & $34.2 \pm 0.6$ \\
\hline \multirow[t]{3}{*}{ II Diabetic } & 19 & 0 & $14 \pm 1$ & $122 \pm 5^{*}$ & $7.80 \pm 0.16$ & $7.8 \pm 0.16$ \\
\hline & & 2.4 & $78 \pm 4$ & $101 \pm 1$ & $0.89 \pm 0.10$ & $13.3 \pm 0.50^{\ddagger}$ \\
\hline & & 4.8 & $174 \pm 6$ & $100 \pm 1$ & $0.36 \pm 0.06$ & $24.8 \pm 0.6^{\ddagger}$ \\
\hline \multirow{3}{*}{$\begin{array}{l}\text { III Diabetic plus } \\
\text { phlorizin }\end{array}$} & 10 & 0 & $13 \pm 1$ & $100 \pm 3$ & $7.34 \pm 0.24$ & $7.34 \pm 0.24$ \\
\hline & & 2.4 & $77 \pm 3$ & $100 \pm 1$ & $0.68 \pm 0.11$ & $19.1 \pm 0.6$ \\
\hline & & 4.8 & $154 \pm 3$ & $102 \pm 2$ & $0.34 \pm 0.12$ & $33.1 \pm 1.1$ \\
\hline \multirow{3}{*}{$\begin{array}{l}\text { IV Sham-operated plus } \\
\text { phlorizin }\end{array}$} & 7 & 0 & $15 \pm 1$ & $99 \pm 2$ & $7.38 \pm 0.17$ & $7.38 \pm 0.17$ \\
\hline & & 2.4 & $84 \pm 3$ & $100 \pm 2$ & $0.70 \pm 0.07$ & $19.1 \pm 0.6$ \\
\hline & & 4.8 & $153 \pm 5$ & $99 \pm 2$ & $0.29 \pm 0.09$ & $34.7 \pm 1.5$ \\
\hline \multirow{3}{*}{$\begin{array}{l}\text { V Phlorizin-treated } \\
\text { diabetics after } \\
\text { stopping phlorizin }\end{array}$} & 4 & 0 & $14 \pm 1$ & $113 \pm 3$ & $7.69 \pm 0.24$ & $7.69 \pm 0.24$ \\
\hline & & 2.4 & $82 \pm 4$ & $102 \pm 1$ & $1.08 \pm 0.07$ & $13.2 \pm 1.2^{\ddagger}$ \\
\hline & & 4.8 & $162 \pm 2$ & $101 \pm 1$ & $0.36 \pm 0.08$ & $25.2 \pm 1.3^{\ddagger}$ \\
\hline
\end{tabular}

${ }^{*} P<0.05$ versus Groups I, III, and IV. ${ }^{\ddagger} P<0.001$ versus Groups I, III, and IV. 
of the insulin-clamp studies. Hepatic glucose production in the postabsorptive state was not significantly different between the five groups (Table II). Suppression of hepatic glucose output by insulin was not significantly different statistically during the 2.4 or $4.8 \mathrm{mU} / \mathrm{kg} \cdot \mathrm{min}$ insulin infusion rates for the five experimental groups. During the highest dose insulin clamp, when the liver can be assumed to be completely suppressed, the rate of exogenous glucose infusion $(34.0 \pm 0.8 \mathrm{mg} / \mathrm{kg} \cdot \mathrm{min})$ closely approximated the rate of disappearance $\left(R_{\mathrm{d}}\right)(34.2 \pm 0.6 \mathrm{mg} /$ $\mathrm{kg} \cdot \mathrm{min})$ as determined from the tritiated glucose. This provides a validation of the tracer methodology in the rat.

The reproducibility of the insulin clamp was demonstrated in the five diabetic rats who were repeatedly studied. The mean rate of glucose metabolism in the first study was $24.9 \pm 1.4 \mathrm{mg} /$ $\mathrm{kg} \cdot \mathrm{min}$ compared with $24.8 \pm 2.2 \mathrm{mg} / \mathrm{kg} \cdot \mathrm{min}$ in the second study.

The fed plasma glucose concentration (2-h value during the MTT) was strongly and inversely correlated with the glucose uptake rate during both steps of the insulin-clamp studies in the three diabetic groups (II, III, and V) $(r=-0.77$ and $r=-0.70$ during the low and high dose insulin-clamp steps, respectively, $P<0.005)$ (Fig. 1). The correlations would persist $(r=-0.81$ and $r=-0.79$, respectively, both $P<0.001$ ) if the two control groups (I and IV) were included in the analysis with the three diabetic groups. A significant inverse correlation $(r=-0.783$, $P<0.001$ ) between the fasting plasma glucose concentration and rate of insulin-mediated glucose uptake was also observed in the three diabetic groups.

\section{Discussion}

Insulin resistance has been demonstrated as a prominent feature in both human and animal models of IDDM and NIDDM (314). However, the pathogenetic sequence of events leading to the emergence of the defect in insulin action remains controversial. In the most general sense, the insulin resistance could be either primary or acquired. A number of studies have attempted to answer this question by examining whether tight metabolic control with insulin can correct the impairment in insulin-mediated glucose disposal in diabetic patients (22-27). The results of such studies (22-27) have consistently demonstrated that intensified insulin therapy improves, but does not normalize, the body's ability to respond to a physiologic increment in the plasma insulin concentration, which suggest that at

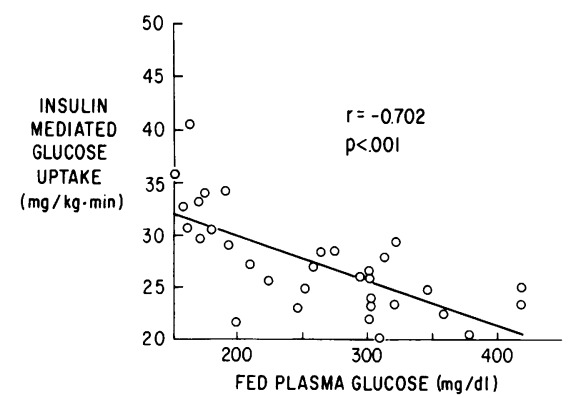

Figure 1. Relationship between the fed (2-h value recorded during the meal tolerance test) plasma glucose concentration and insulin-mediated glucose disposal during the $4.8 \mathrm{mU} / \mathrm{kg} \cdot \mathrm{min}$ euglycemic insulin clamp in diabetic rats (groups II, III, and V). least part of the insulin resistance is acquired. However, these observations do not define whether some metabolic derangement that occurs secondary to the insulin deficiency or insulin deficiency per se is responsible for the development of insulin resistance since treatment simultaneously corrects both the insulin lack and its resultant metabolic disturbances. This distinction has received renewed interest by the recent studies of Weir et al. $(15,28)$, which have provided evidence that hyperglycemia per se exerts a deleterious effect on insulin secretion by the $\beta$ cell. In a recent review Unger and Grundy (18) have proposed that hyperglycemia may also be responsible for the development of insulin resistance in diabetes mellitus. Accordingly, Lorenzi et al. have shown that human endothelial cells that are cultured in a high glucose medium manifest decreased growth capacity and multiple defects in DNA replication (29). However, a direct deleterious effect of hyperglycemia on insulin-mediated glucose metabolism has yet to be demonstrated either in vivo or in vitro. In an attempt to examine this question, we have employed the euglycemic insulin-clamp technique to quantitate insulin-mediated glucose utilization in diabetic rats before and after correction of hyperglycemia with phlorizin, an inhibitor of renal tubular glucose transport.

Rats were made diabetic by surgically removing $90 \%$ of the pancreas $(15,19)$, which resulted in moderate fasting hyperglycemia and glucose intolerance after both MTT and OGTT (Table I). Although fasting insulin levels remained normal in our diabetic rats, the plasma insulin response to hyperglycemia was markedly impaired (Table I). Tissue sensitivity to insulin, quantitated 6 wk after partial pancreatectomy, was reduced by $27-$ $29 \%(P<0.001)$ (Table II), a decrease in insulin-mediated glucose metabolism that is much greater than can be explained by the variability of the insulin-clamp technique in the rat.

The development of insulin resistance after an initial defect in insulin secretion is consistent with previous observations in dogs who are made partially insulin deficient with alloxan or streptozotocin (9-11). To define if the development of insulin resistance after pancreatectomy resulted from insulin deficiency or from hyperglycemia, animals received daily injections of phlorizin to induce a state of persistent renal glucosuria. Fasting plasma glucose concentration was completely normalized in phlorizin-treated diabetic rats (Table I), and was similar in the phlorizin-treated diabetic and control rats at $1 \mathrm{~h}$ during the MTT; the fed plasma glucose level at $2 \mathrm{~h}$ was slightly greater in the phlorizin-treated diabetic group compared with the sham-operated control group ( $171 \pm 4 \mathrm{vs.} 140 \pm 1 \mathrm{mg} / \mathrm{dl}$, respectively). Altogether, these results indicate that phlorizin largely normalized the plasma glucose profile in diabetic animals. Importantly, neither the fasting nor meal-stimulated plasma insulin concentrations increased after phlorizin treatment in the diabetic rats; nonetheless, insulin-mediated glucose disposal was returned to normal. Since phlorizin failed to enhance insulin sensitivity in sham-operated control rats, the improvement in insulin action in the diabetic rats can not be attributed to a nonspecific effect of phlorizin. These results strongly suggest that hyperglycemia per se exerts a deleterious effect on insulin-mediated glucose disposal in vivo. To further examine this question, four diabetic rats in group III were restudied after discontinuation of the phlorizin for $2 \mathrm{wk}$ (group V) at which time the fasting and postmeal plasma glucose concentrations returned to levels similar to those observed in the diabetic (group II) rats, without any change in plasma insulin levels. Repeat of euglycemic insulinclamp studies in group $\mathrm{V}$ animals revealed a degree of insulin 
resistance that was nearly identical to that observed in group II diabetic rats. When the three groups of diabetic rats (II, III, and V) are considered together, a strong, negative correlation between the postmeal plasma glucose concentration and the rate of insulin-mediated glucose metabolism was observed (Fig. 1). A similar inverse correlation was observed between the fasting glucose and glucose utilization. These results provide further support that hyperglycemia per se can lead to the development of insulin resistance, and suggest that the severity of the hyperglycemia is related to the strength of the insulin resistance.

Our findings also help to elucidate the tissues responsible for the development of the insulin resistance after partial pancreatectomy and its correlation with phlorizin. After the infusion of insulin, tissue glucose uptake is stimulated and endogenous (hepatic) glucose production is suppressed. Since the present studies were performed with tritiated glucose, we were able to quantitate changes in hepatic glucose production in response to hyperinsulinemia. As can be seen in Table II the ability of insulin to inhibit hepatic glucose output in diabetic rats was neither impaired nor altered by phlorizin treatment in either diabetic or control groups. Although we can't exclude the possibility that chronic hyperglycemia might impair the ability of lower plasma insulin levels (i.e., $<70-80 \mu \mathrm{U} / \mathrm{ml}$ ) to effectively inhibit hepatic glucose production, under the present experimental conditions the insulin resistance in diabetic rats is clearly due primarily to a defect in tissue glucose uptake. These observations are similar to those previously reported by us in non-insulin-dependent diabetic man $(3,4$, and 6$)$. Further, clearly the improvement in insulin action in diabetic rats after phlorizin administration results from an enhancement in tissue glucose uptake and not due to a more effective suppression of hepatic glucose output. Since, under euglycemic hyperinsulinemic conditions, the majority of an infused glucose load is used by peripheral tissues $(6,30$, and 31 ), and since adipose tissue is responsible for the uptake of $<1-2 \%$ of an infused/ingested glucose load $(32,33)$, it is likely that the deleterious effect of chronic hyperglycemia on insulinmediated glucose uptake is primarily directed at muscle tissue.

In summary, the present results demonstrate that partial pancreatectomy in the rat, which results in moderate fasting hyperglycemia and postmeal glucose intolerance, leads to the development of insulin resistance. Correction of the hyperglycemia by phlorizin restores insulin-mediated glucose disposal to normal without change in either fasting or glucose-stimulated insulin levels. Discontinuation of phlorizin in diabetic rats leads to the reemergence of hyperglycemia and insulin resistance. These observations provide evidence that hyperglycemia per se may contribute to the development of insulin resistance in diabetes mellitus, and indicate that it may be very difficult to assign primary versus secondary roles to presence of insulin resistance in non-insulin-dependent diabetic individuals.

\section{Acknowledgments}

The authors would like to thank Dr. Gordon Weir and Susan BonnerWeir for teaching them how to perform the partial pancreatectomies. We are indebted to Mrs. Carrie Toth and Miss Jo Anne Palmieri for their expert secretarial assistance.

Dr. Rossetti is the recipient of a grant from the Italian Ministero della Pubblica Istruzione and Juvenile Diabetes Foundation fellowship 386266. Dr. Gerald Shulman is the recipient of National Institutes of Health SERCA award AM-01248 and a grant from the Juvenile Diabetes Foundation. Dr. Papachristou is the recipient of the G-58 scholarship from the Onassis Public Benefit Foundation.

\section{References}

1. Ward, W. K., D. C. Bolgiano, B. McKnight, J. B. Halter, and D. Porte. 1984. Diminished beta cell secretory capacity in patients with noninsuln-dependent diabetes. J. Clin. Invest. 74:1318-1328.

2. Efendic, S., A. Wajnot, E. Cerasi, and R. Luft. 1980. Insulin release, insulin sensitivity and glucose intolerance. Proc. Natl. Acad. Sci. USA. 77:7425-7429.

3. DeFronzo, R. A., E. Ferrannini, and V. Koivisto. 1983. New concepts in the pathogenesis of non-insulin-dependent diabetes mellitus. Am. J. Med. 74(Suppl. 1A):52-81.

4. DeFronzo, R. A., D. Deibert, R. Hendler, and P. Felig. 1982. Insulin sensitivity and insulin binding to monocytes in maturity-onset diabetes. J. Clin. Invest. 63:939-946.

5. DeFronzo, R. A., R. Hendler, and D. Simonson. 1982. Insulin resistance is a prominent feature of insulin-dependent diabetes. Diabetes. 31:795-801.

6. DeFronzo, R. A., R. Gunnarsson, O. Bjorkman, and J. Wahren. 1985. Effect of insulin on peripheral and splanchnic glucose metabolism in noninsulin-dependent (type II) diabetes mellitus. J. Clin. Invest. 76: 149-155.

7. Kolterman, O. G., R. S. Gray, J. Griffin, P. Burstein, J. Insel, J. A. Scarlett, and J. M. Olefsky. 1981. Receptor and postreceptor defects contribute to the insulin resistance in noninsulin-dependent diabetes mellitus. J. Clin. Invest. 68:957-969.

8. Hollenbeck, C. B., Y.-D. I. Chen, and G. M. Reaven. 1984. A comparison of the relative effects of obesity and non-insulin-dependent diabetes mellitus on in vivo insulin-stimulated glucose utilization. $\mathrm{Di}$ abetes. 33:622-626.

9. Reaven, G. M., W. S. Sageman, and R. S. Swenson. 1977. Development of insulin resistance in normal dogs following alloxan-induced insulin deficiency. Diabetologia. 13:459-462.

10. Pupo, A. A., M. J. M. Ursich, E. Iamaguchi, and F. G. Vasconcellos. 1976. Acute and late phase insulin secretion and glucose tolerance in mild alloxan diabetes in dog. Diabetes. 25:161-166.

11. Bevilacqua, S., E. J. Barret, D. Smith, D. C. Simonson, P. Bratusch-Marrain, E. Ferrannini, and R. A. DeFronzo. 1985. Hepatic and peripheral insulin resistance following streptozocin-induced insulin deficiency in the dog. Metab. Clin. Exp. 34:817-825.

12. Levy, J., J. R. Gavin III, A. Fausto, R. L. Gingerich, and L. V. Avioli. 1984. Impaired insulin action in rats with non-insulin dependent diabetes. Diabetes. 33:901-906.

13. Dall'Aglio, E., H. Chang, C. B. Hollenbeck, C. E. Mondon, C. Sims, and G. M. Reaven. 1985. In vivo and in vitro resistance to maximal insulin stimulated glucose disposal in insulin deficiency. Am. J. Physiol. 249:E312-E316.

14. Le Marchand-Brustel, Y., and P. Freychet. 1979. Effect of fasting and streptozocin diabetes on insulin binding and action in the isolated mouse soleus muscle. J. Clin. Invest. 64:1505-1515.

15. Bonner-Weir, S., D. F. Trent, and G. C. Weir. 1983. Partial pancreatectomy in the rat and subsequent defect in glucose induced insulin release. J. Clin. Invest. 71:1544-1553.

16. Grill, V., and E. Rundfeldt. 1986. Abnormalities of insulin responses after ambient and previous exposure to glucose in streptozocin diabetic and dexamethasone-treated rats. Diabetes. 35:44-51.

17. Starke, A., S. Grundy, D. McGarry, and R. Unger. 1985. Correction of hyperglycemia with phlorizin restores the glucagon response to glucose in insulin-deficient dogs: implication for human diabetes. Proc. Natl. Acad. Sci. USA. 82:1544-1546.

18. Unger, R. H., and S. Grundy. 1985. Hyperglycemia as an inducer as well as a consequence of impaired islet cell function and insulin resistance: implication for the management of diabetes. Diabetologia. 28: 119-121.

19. Foglia, V. G. 1944. Caracteristicas de la diabetes en la rata. Rev. Soc. Argent. Biol. 20:21-37.

20. DeFronzo, R. A., J. Tobin, and R. Andres. 1979. Glucose clamp technique: a method for quantifying insulin secretion and resistance. Am. J. Physiol. 237:E214-E223. 
21. Rossetti, L., G. Klein-Robbenhaar, G. Gibisch, D. Smith, and R. A. DeFronzo. 1987. Effect of insulin on renal potassium metabolism. Am. J. Physiol. 252:f60-f64.

22. Scarlett, J. A., R. S. Gray, J Griffin, J. M. Olefsky, and O. G. Kolterman. 1982. Insulin treatment reverses the insulin resistance of Type II diabetes mellitus. Diabetes Care. 5:353-363.

23. Lager, I., P. Lonroth, H. Von Schenck, and U. Smith. 1983 Reversal of insulin resistance in Type I diabetes after treatment with continuous subcutaneous insulin infusion. Br. Med. J. 287:1661-1664.

24. Revers, R. R., O. G. Kolterman, J. A. Scarlett, R. S. Gray, and J. M. Olefsky. 1984. Lack of in vivo insulin resistance in controlled insulin-dependent, Type I diabetic patients. J. Clin. Endocrinol. \& Metab. 58:353-358.

25. Beck-Nielsen, H., B. Richelsen, C. Hasling, O. H. Nielsen, L. Hedding, and N. S. Sorensen. 1984. Improved in vivo insulin effect during continuous subcutaneous insulin infusion in patients with IDDM. Diabetes. 33:832-837.

26. Simonson, D. C., W. C. Tamborlane, R. S. Sherwin, J. D. Smith, and $R$. A. DeFronzo. 1985. Improved insulin sensitivity in patients with Type I diabetes mellitus after CSII. Diabetes. 34(Suppl. 3):80-86.

27. Garvey, W. T., J. M. Olefsky, R. F. Griffin, R. F. Hamman, and
O. G. Kolterman. 1985. The effect of insulin treatment on insulin secretion and insulin action in Type II diabetes mellitus. Diabetes. 34: 222-237.

28. Leahy, J. L., and G. C. Weir. 1985. Unresponsiveness to glucose in a streptozocin model of diabetes. Diabetes. 34:653-659.

29. Lorenzi, M., E. Cagliero, and S. Toledo. 1985. Glucose toxicity for human endothelial cells in culture. Diabetes. 34:621-627.

30. DeFronzo, R. A., E. Ferrannini, R. Hendler, P. Felig, and J. Wahren. 1983. Regulation of splanchnic and peripheral glucose uptake by insulin and hyperglycemia in man. Diabetes. 32:35-45.

31. DeFronzo, R. A., E. Jacot, E. Jequier, E. Maeder, and J. P. Felber. 1981. The effect of insulin on the disposal of intravenous glucose: results from indirect calorimetry and hepatic and femoral venous catheterization. Diabetes. 30:1000-1007.

32. Bjorntorp, P., M. Krotkiewski, B. Larson, and A. Soimlo-Szuck. 1970. Effects of feeding states on lipid radioactivity in liver, muscle, and adipose tissue after injection of labeled glucose in the rat. Acta Physiol. Scand. 80:28-38.

33. Bjorntorp, P., P. Berchtold, and B. Larson. 1971. The glucose uptake of human adipose tissue in obesity. Eur. J. Clin. Invest. 1:480483. 